\title{
ChemComm
}

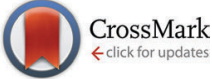

Cite this: Chem. Commun., 2016, 52,8719

Received 31st May 2016

Accepted 16th June 2016

DOI: $10.1039 / c 6 c c 04549 a$

www.rsc.org/chemcomm

\section{Using steric bulk for selective recognition; blocking the binding site to differentiate guests $\dagger$}

\author{
Ryan N. Robson and Frederick M. Pfeffer*
}

\begin{abstract}
Selectivity is demonstrated in a supramolecular host:guest system using a receptor with a non-linear binding site. For the "open" receptor 1 strong binding for both flexible and rigid guests was observed. Receptor 2, with a "blocked" binding site, also bound flexible guests effectively but its affinity for rigid guests was 50 fold lower.
\end{abstract}

The concepts of preorganisation and complementarity are central to supramolecular chemistry. ${ }^{1,2}$ It is accepted that through the careful application of these concepts that a host can be constructed with high selectivity for a specific guest. ${ }^{2}$

In Nature recognition is also achieved using non-linear binding sites, for example, the well-known thiazolidinedione insulin sensitizer rosiglitazone (marketed as Avandia) adopts a " $U$ " shape when bound to its target the peroxisome proliferatoractivated receptor (PPAR $\gamma$ ). ${ }^{3}$ As long as the guest can adopt a low energy conformation to accommodate a "twisted" or "hindered" binding site then strong interactions, and in turn biological activity, can be achieved. The pharmaceutical guest rosiglitazone can assume the required non-linear conformation due to judiciously placed flexible methylene and ethylene links. Not all ligands, substrates, and even pharmaceutical guests can adopt such a conformation and in this way enhanced selectivity can be achieved.

In supramolecular chemistry a great deal of attention has been devoted to designing and synthesising perfectly matched (preorganised and complementary) host:guest systems. The use of hosts with non-linear binding sites/clefts to elicit selectivity amongst guests is as yet not well explored.

Herein we report two new hosts 1 and 2 (Fig. 1) for the binding of dicarboxylates. Host 2 was designed to favour the binding of flexible guests and its structure comprises a bisurea cleft that is centrally functionalised with a blocking unit that prevents

Centre for Chemistry and Biotechnology, School of Life and Environmental Sciences, Deakin University, Waurn Ponds, Victoria, 3216, Australia.

E-mail: fred.pfeffer@deakin.edu.au

$\dagger$ Electronic supplementary information (ESI) available: Detailed experimental procedures, ${ }^{1} \mathrm{H},{ }^{13} \mathrm{C}$ and ${ }^{19} \mathrm{~F}$ NMR spectra of compounds, as well as all titration isotherms. See DOI: 10.1039/c6cc04549a

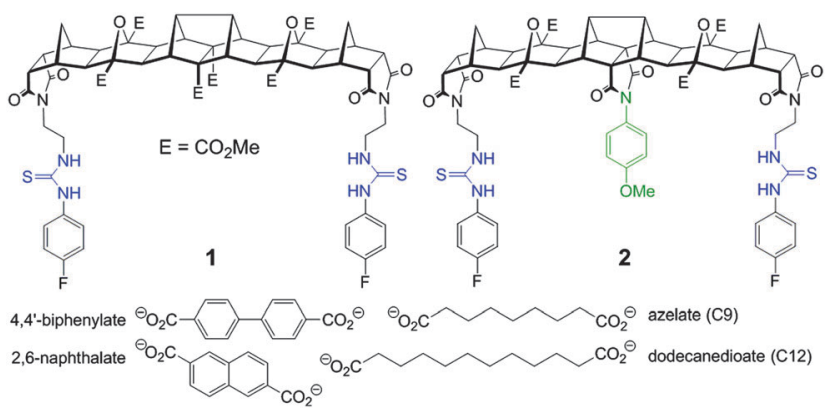

Fig. 1 Structure of fused polynorbornane hosts 1 and 2 highlighting the sterically restricted cleft of host $\mathbf{2}$. Also shown are the four dicarboxylate guests used in this study.

linear "end-to-end" binding. While the synthesis of both 1 and 2 was broadly based on previous polynorbornyl bis-thiourea systems, ${ }^{4}$ a unique central unit was required that could be further functionalised. Hedaya diene 3 (Scheme 1), a diester synthesised by a tandem Diels-Alder reaction, ${ }^{5}$ was identified as ideally suited for further modification. ${ }^{6}$

Saponification of diene 3 to the diacid was followed by dehydration (using $\mathrm{Ac}_{2} \mathrm{O}$ ) to the corresponding anhydride. Reaction of the anhydride with 4-methoxyaniline gave the desired centrally functionalised imide 4 in $21 \%$ yield (Scheme 1, see ESI, $\dagger$ for a detailed description of all synthetic procedures). The microwave mediated 1,3 dipolar cycloaddition ${ }^{7}$ between either 3 or 4 and the carbonyl ylide generated from cyclobutane epoxide $\mathbf{5}^{8}$ afforded the fused polynorbornane frameworks 6 and 7 (65\% and $71 \%$ yield respectively). A two-step protocol involving removal of the protecting groups (TFA/ $\mathrm{CH}_{2} \mathrm{Cl}_{2}$ ) then immediate reaction with 4-fluorophenylisothiocyanate gave the new thiourea hosts 1 and 2 in $77 \%$ and $73 \%$ yield respectively. The new compounds were fully characterised using ${ }^{1} \mathrm{H},{ }^{13} \mathrm{C}$ and ${ }^{19} \mathrm{~F}$ NMR spectroscopy and for 2 the appearance of two sets of $\mathrm{AB}$ pairs in the ${ }^{1} \mathrm{H}$ spectrum clearly indicated the central and end functionalised para substituted aromatics. Due to the primarily aliphatic nature of the frameworks the region of the spectrum containing the urea $\mathrm{N}-\mathrm{H}$ resonances $(\delta=9.53 \& 7.67 \mathrm{ppm}$ for 1 and $\delta=9.58 \& 7.71 \mathrm{ppm}$ for 2$)$ was free 


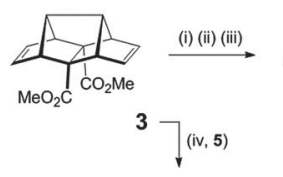

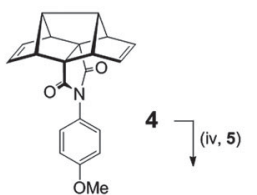
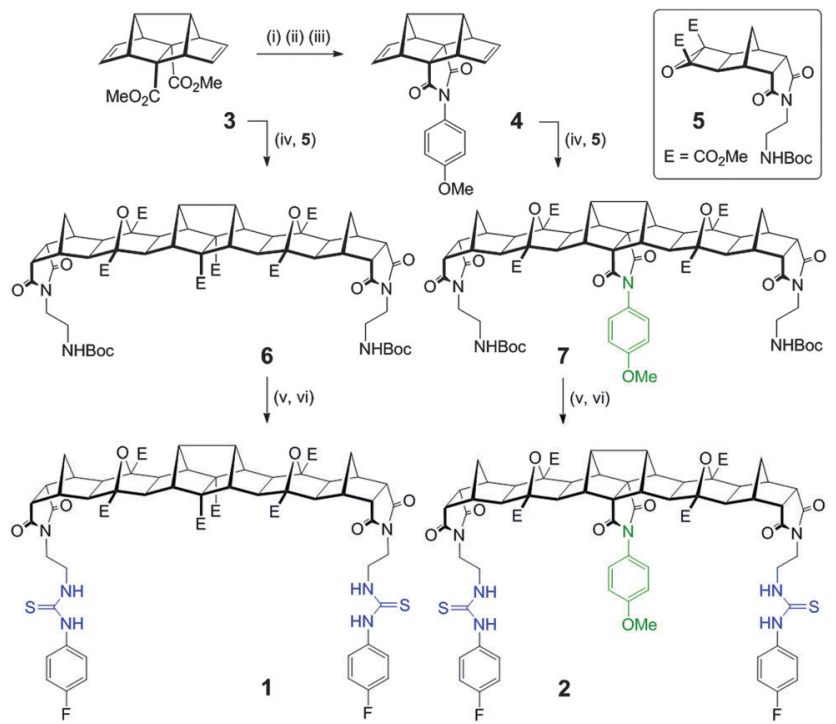

Scheme 1 Synthesis of new hosts 1 and 2. Reagents and conditions: (i) $\mathrm{KOH}, \mathrm{CH}_{3} \mathrm{OH}, 60{ }^{\circ} \mathrm{C}, 4 \mathrm{~h}, 89 \%$ (ii) $\mathrm{Ac}_{2} \mathrm{O}, \mathrm{CH}_{2} \mathrm{Cl}_{2}, 40{ }^{\circ} \mathrm{C}, 4 \mathrm{~h}, 99 \%$ (iii) 4-methoxyaniline, $\mathrm{PhCH}_{3}, 150{ }^{\circ} \mathrm{C}$ ( $\mu \mathrm{w}$ ), $30 \mathrm{~min}, 21 \%$ (iv) 5 (2 equiv.), $150{ }^{\circ} \mathrm{C}(\mu \mathrm{w}), 10 \mathrm{~min}, 65 \%$ for $6,71 \%$ for 7 (v) $20 \%$ TFA in $\mathrm{CH}_{2} \mathrm{Cl}_{2}, 4 \mathrm{~h}$ (vi) 4-fluorophenylisothiocyanate, $\mathrm{NEt}\left(\mathrm{Pr}_{2}, \mathrm{CHCl}_{3}, 24 \mathrm{~h}, 77 \%\right.$ for $1,73 \%$ for 2

from other resonances making them ideally suited for ${ }^{1} \mathrm{H}$ NMR titration experiments to evaluate binding.

Binding studies were performed using both the rigid dicarboxylates (2,6-naphthalate and 4,4'-biphenylate, Fig. 1$)$ as well as flexible dicarboxylates of similar length (azelate (C9) and dodecanedioate (C12), Fig. 1). All ${ }^{1} \mathrm{H}$ NMR titrations were performed in $d_{6}$-DMSO at a host concentration of $2.5 \mu \mathrm{M}$. Binding constants (see Table 1) were determined using global fitting (Bindfit software). ${ }^{9}$ All isotherms with fitplots are provided in the ESI. $\dagger$

For new bisurea host $\mathbf{1}$ binding of both the rigid and flexible guests was comparable (Table 1). For example host 1 bound both naphthalate and azelate (C9) in a strong 1:1 fashion $(\log K=3.7$ and 4.3 respectively, Table 1$)$. The results clearly indicate that the new bisurea host is well suited to the binding of larger dicarboxylates. These results also clearly reinforce the fact that for preorganised bisurea clefts that do not possess some form of additional means of binding site discrimination little selectivity is achievable between guests of similar length.

The binding behaviour of the new hosts 1 and 2 to both flexible guests was near identical. Indeed, both 1 and 2 bound azelate (C9) equally effectively and the binding isotherms (Fig. 2) and in turn the binding constants $(\log K=4.3$ and

Table 1 Binding constants $\left(\log K_{1: 1}\right)^{a}$ for hosts 1 and $\mathbf{2}$ with both rigid and flexible guests

\begin{tabular}{lllll}
\hline \multirow{2}{*}{ Host } & \multicolumn{4}{l}{ Dicarboxylate guest } \\
\cline { 2 - 5 } & Naphthalate & Biphenylate & Azelate C9 & Dodecanedioate C12 \\
\hline $\mathbf{1}$ & $3.7(6 \%)$ & $3.5(4 \%)$ & $4.3(14 \%)$ & $4.4(13 \%)$ \\
$\mathbf{2}$ & $2.8(1 \%)$ & $2.7(1 \%)$ & $4.5(12 \%)$ & $4.1(14 \%)$
\end{tabular}

${ }^{a} \log K_{1: 1}$ as determined from the titration isotherm with associated fitting error $(\%){ }^{9}$
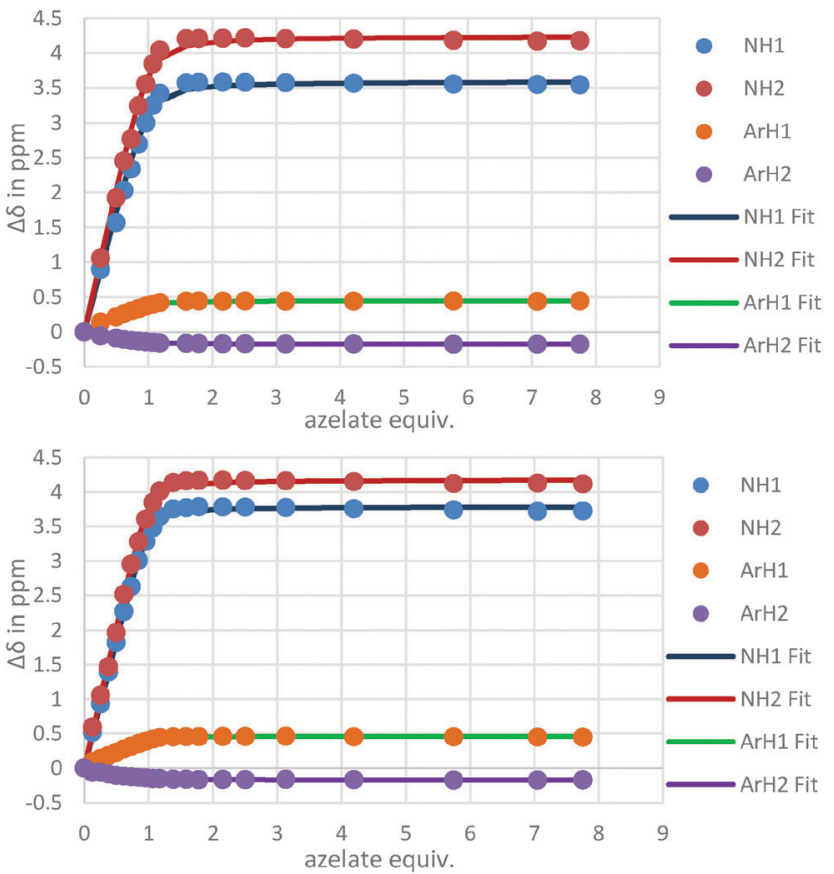

Fig. 2 Isotherms resulting from the ${ }^{1} \mathrm{H}$ NMR titrations of hosts 1 and 2 with azelate (C9).

$\log K=4.5$ respectively) for this anion were near identical indicating that strong binding was taking place regardless of the central methoxyphenyl group (Fig. 3).

While the central methoxyphenyl group in $\mathbf{2}$ had little influence on the binding of flexible guests it had significant influence on the binding of rigid dicarboxylates of similar length. Indeed, compared to host 1 the binding of the same guest was an order of magnitude less potent; for example the binding of 2 to 2,6-naphthalate was modest $(\log K=2.8)$ whereas the unencumbered host 1 bound this guest much more effectively $(\log K=3.7)$.

For host 2 the discrimination of flexible versus rigid guests was highlighted in the binding of azelate (C9) versus the similarly sized 2,6-naphthalate $(\log K=4.5$ versus $\log K=2.8$, Fig. 4). The difference in binding constants amounts to 50 fold selectivity for the flexible guest over the rigid.

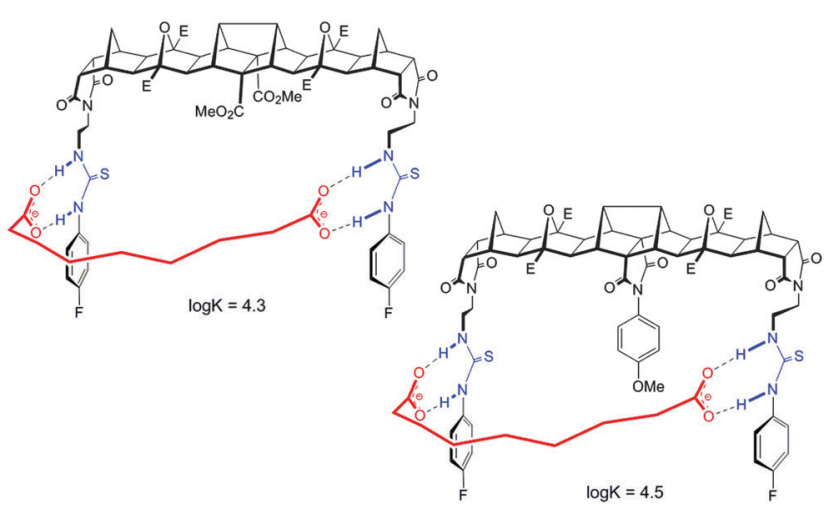

Fig. 3 Proposed binding conformation of hosts $\mathbf{1}$ and $\mathbf{2}$ with azelate (C9). 

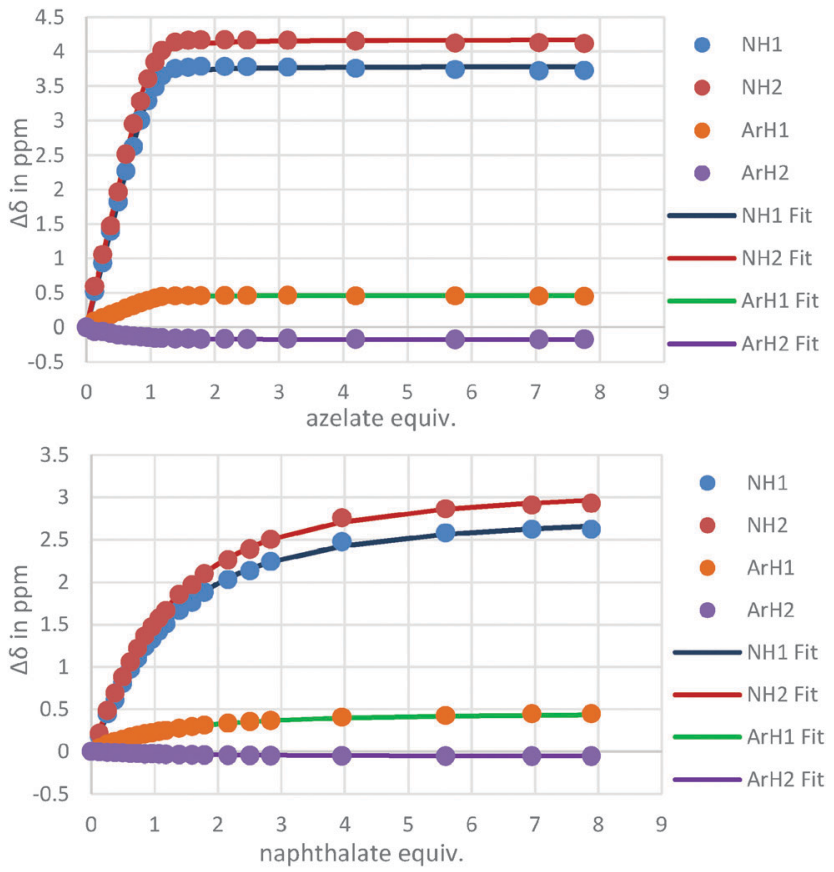

Fig. 4 Isotherms resulting from the ${ }^{1} H$ NMR titrations of hosts 2 with azelate (C9) (top) and naphthalate (bottom) showing the clear difference in binding behaviour.

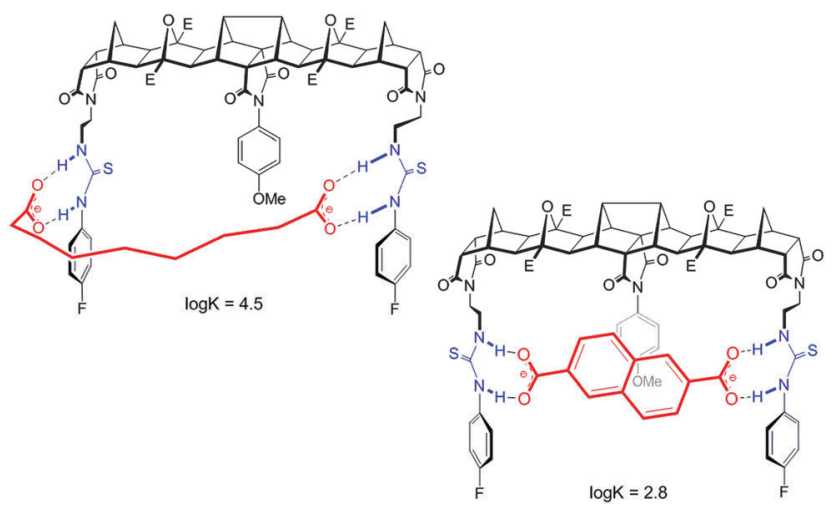

Fig. 5 Proposed binding of host 2 with azelate (C9) and naphthalate.

Features of both host 2 and the guest make this possible. First, for the host, with ethylene linkers to the thiourea groups, a reorientation of the $\mathrm{H}$ bond donors to face away from the central cleft is possible and as such a non-linear binding site is readily created. Second and most importantly, guests such as azelate are highly flexible and as such can adopt a low energy "U" shape conformation that can interact with the host regardless of the central unit. Due to the central group of 2 , the rigid guests, despite their appropriate size, cannot form strong linear hydrogen bonds with the thiourea groups (Fig. 5).
In conclusion we have successfully demonstrated that selectivity in supramolecular recognition can be achieved using a steric block to discriminate against guests that cannot adopt the " $U$ " shape geometry required for strong binding. Such a general strategy is likely to be particularly useful in the binding of larger, typically more challenging substrates.

FMP thanks the Australian Research Council (ARCDP0140100227) and Centre for Chemistry and Biotechnology for financial support. The authors would also like to acknowledge the Australian Research Council for funding the Magnetic Resonance Facility at Deakin through LIEF grant LE110100141.

\section{Notes and references}

1 Anion Receptor Chemistry, ed. J. L. Sessler, P. A. Gale and W.-S. Cho, The Royal Society of Chemistry, Cambridge, 2006; Supramolecular Chemistry: from molecules to nanomaterials, ed. J. W. Steed and P. A. Gale, John Wiley and Sons, Chichester, 2012.

2 D. J. Cram, Science, 1988, 240, 760-767; D. Cram, Angew. Chem., Int. Ed., 1988, 27, 1009-1020; K. P. McDonald, Y. Hua, S. Lee and A. H. Flood, Chem. Commun., 2012, 48, 5065-5075; H. T. Ngo, X. J. Liu and K. A. Jolliffe, Chem. Soc. Rev., 2012, 41, 4928-4965; E. M. Boyle, S. Comby, J. K. Molloy and T. Gunnlaugsson, J. Org. Chem., 2013, 78, 8312-8319; P. A. Gale, N. Busschaert, C. J. E. Haynes, L. E. Karagiannidis and I. L. Kirby, Chem. Soc. Rev., 2014, 43, 205-241; P. Rios, T. S. Carter, T. J. Mooibroek, M. P. Crump, M. Lisbjerg, M. Pittelkow, N. T. Supekar, G.-J. Boons and A. P. Davis, Angew. Chem., Int. Ed., 2016, 55, 3387-3392.

3 R. T. Nolte, G. B. Wisely, S. Westin, J. E. Cobb, M. H. Lambert, R. Kurokawa, M. G. Rosenfeldk, T. M. Willson, C. K. Glass and M. V. Milburn, Nature, 1998, 395, 137-143; H. E. Xu, M. H. Lambert, V. G. Montana, K. D. Plunket, L. B. Moore, J. L. Collins, J. A. Oplinger, S. A. Kliewer, R. T. Gampe Jr., D. D. McKee, J. T. Moore and T. M. Willson, Proc. Natl. Acad. Sci. U. S. A., 2001, 98, 13919-13924.

4 A. J. Lowe and F. M. Pfeffer, Chem. Commun., 2008, 1871-1873; A. J. Lowe and F. M. Pfeffer, Org. Biomol. Chem., 2009, 7, 4233-4240; A. J. Lowe, B. M. Long and F. M. Pfeffer, J. Org. Chem., 2012, 77, 8507-8517; A. J. Lowe, B. M. Long and F. M. Pfeffer, Chem. Commun., 2013, 49, 3376-3388; B. M. Long and F. M. Pfeffer, Chem. - Asian J., 2014, 9, 1091-1098.

5 D. McNeil, B. R. Vogt, J. J. Sudol, S. Theodoropulos and E. Hedaya, J. Am. Chem. Soc., 1974, 96, 4673-4674; L. A. Paquette, M. J. Wyvratt, H. C. Berk and R. E. Moerck, J. Am. Chem. Soc., 1978, 100, 5845-5855; R. T. Taylor, M. W. Pelter and L. A. Paquette, Organic Syntheses, Coll., 1993, vol. 8, p. 298; R. T. Taylor, M. W. Pelter and L. A. Paquette, Organic Syntheses, Coll., 1990, vol. 68, p. 198.

6 M. Abou-Gharbia, U. R. Patel, M. B. Webb, J. A. Moyer, T. H. Andree and E. A. Muth, J. Med. Chem., 1988, 31, 1382-1392; M. Golic, M. R. Johnston, D. Margetic, A. C. Schultz and R. N. Warrener, Aust. J. Chem., 2006, 59, 899-914; M. D. Duque, C. Ma, E. Torres, J. Wang, L. Naesens, J. Juarez-Jimenez, P. Camps, F. Javier Luque, W. F. DeGrado, R. A. Lamb, L. H. Pinto and S. Vazquez, J. Med. Chem., 2011, 54, 2646-2657; M. D. Johnstone, E. K. Schwarze, G. H. Clever and F. M. Pfeffer, Chem. - Eur. J., 2015, 21, 3948-3955.

7 R. C. Foitzik, A. J. Lowe and F. M. Pfeffer, Tetrahedron Lett., 2009, 50, 2583-2584.

8 F. M. Pfeffer, T. Gunnlaugsson, P. Jensen and P. E. Kruger, Org. Lett., 2005, 7, 5357-5360; F. M. Pfeffer, P. E. Kruger and T. Gunnlaugsson, Org. Biomol. Chem., 2007, 5, 1894-1902.

9 http://supramolecular.org, accessed 15th May, 2016; P. Thordarson, Chem. Soc. Rev., 2011, 40, 1305-1323; A. J. Lowe, F. M. Pfeffer and P. Thordarson, Supramol. Chem., 2012, 24, 585-594. 